\title{
PEDAGOGIA EMPRESARIAL: O PAPEL DO PEDAGOGO EM ESPAÇOS NÃO FORMAIS DE EDUCAÇÃO - PERSPECTIVAS, DIVERSIDADES E CONTEXTOS
}

\author{
BUSINESS PEDAGOGY: THE ROLE OF THE PEDAGOGUE IN \\ NON-FORMAL EDUCATIONAL SPACES - PERSPECTIVES, \\ DIVERSITIES AND CONTEXTS
}

Jaqueline Silva de Jesus ${ }^{1}$ Marcelo Máximo Purificação ${ }^{2}$ Elisângela Maura Catarino ${ }^{3}$

\begin{abstract}
RESUMO
O presente estudo foi desenvolvido no âmbito do curso de licenciatura em Pedagogia, do Centro Universitário de Mineiros - UNIFIMES, como prérequisito para integralização do mesmo. Partimos do pressuposto que a globalização, os avanços tecnológicos e científicos trouxeram novas frentes de trabalhos, modificando os tradicionais perfis das empresas e organizações sociais que, cada dia mais, buscam profissionais com perfis multidisciplinares, proativos, que possam contribuir nas relações (inter) pessoais. Isso vem reverberando na universidade que, assim como a escola básica, entrou nesse contexto marcado pelo discurso do processo de educacionalização social - que é o fenômeno/ obsessão contemporânea pela educação. Com a educacionalização, acredita-se que a educação, como centro do processo de humanização, poderá resolver problemas de ordem diversas. A partir dessa perspectiva dialógica neoliberal, o mercado vem abrindo possibilidades para uma inserção cada vez maior de licenciados em contextos não formais de educação. Nesse bojo está o/a licenciado/a em Pedagogia, cuja formação inter, pluri e transdisciplinar o/a habita à prática e à colaboração em projetos de contextos diversos. O objetivo cunhado para este estudo foi analisar, a partir de anúncios de trabalhos, a inserção de pedagogos no mercado, em espaços não formais de educação, no contexto temporal de março a novembro de 2020, associando com o processo de educacionalização social. A metodologia utilizada foi a da pesquisa bibliográfica, ancorada em estudos exploratórios, com método de análise qualitativa a partir das informações obtidas nos anúncios de trabalho e no aparato teórico. À guisa de conclusão, pontuamos que: (i) o curso de Pedagogia tem um grande potencial de empregabilidade, dentro das licenciaturas é o curso que mais emprega; (ii) que em espaços não formais de educação o/a pedagogo/a exerce uma multiplicidade de práticas e que algumas estão bem distantes do seu eixo de formação (III) que a Pedagogia empresarial é um campo próspero e em ascensão com perspectiva de projetar o/a licenciado/a em Pedagogia em contextos de práticas bem diversificados, no entanto, chamamos a atenção para processo de precarização da profissão que se
\end{abstract}

\footnotetext{
${ }^{1}$ Graduada em Pedagogia pelo Centro Universitário de Mineiros - UNIFIMES; E-mail: mgeiza68@ http://lattes.cnpq.br/4037318962796605.

2 Pós-doutor em Educação pela Faculdade de Psicologia e Ciências da Educação da Universidade de Coimbra (U.C). Doutor em Ciências da Religião pela Pontifícia Universidade Católica de Goiás - PUC-Goias. Doutor em Ensino pela Universidade do Vale do Taquari -UNIVATES. Professor Titular no Centro Universitário de Mineiros - UNIFIMES. E-mail: $\underline{\text { maximo@unifimes.edu.br . Orcid: https://orcid.org/0000-0002-4788-016X }}$ Lattes: http://lattes.cnpq.br/5221482223498714.

3 Pós-doutora em Educação pela Escola Superior de Educação de Coimbra - ESEC. Doutora em Ciências da Religião pela Pontifícia Universidade Católica de Goiás - PUC-Goias. Professora Titular no Centro Universitário de Mineiros - UNIFIMES. E-mail: maura@unifimes.edu.br. Orcid: https://orcid.org/0000-0003-4185-8911 Lattes: http://lattes.cnpq.br/7368643483268279.
} 
instala nesse deslocamento. Esse deslocamento do pedagogo para outros espaços também é foco de discussão entre especialistas da área da Educação.

Palavras-chave: Pedagogia Empresarial; Educação; Espaços formais e não formais; Contextos.

\begin{abstract}
This study was developed within the scope of the degree course in Pedagogy, from the Centro Universitário de Mineiros - UNIFIMES, as a prerequisite for its completion. We assume that globalization, technological and scientific advances have brought new fronts of work, changing the traditional profiles of companies and social organizations that, each day more, seek professionals with multidisciplinary, proactive profiles, who can contribute to (inter) personal relationships . This has reverberated in the university, which, like the basic school, has entered this context marked by the discourse of the process of social education - which is the phenomenon / contemporary obsession with education. With education, it is believed that education, as the center of the humanization process, can solve different problems. From this neoliberal dialogical perspective, the market has opened up possibilities for an increasing insertion of graduates in non-formal contexts of education. In this context is the Pedagogy graduate, whose inter, pluri and transdisciplinary training inhabits him / her in the practice and collaboration in projects of different contexts. The objective coined for this study was to analyze, from job advertisements, the insertion of pedagogues in the market, in non-formal educational spaces, in the temporal context from March to November 2020, associating with the process of social education. The methodology used was that of bibliographic research, anchored in exploratory studies, with a qualitative analysis method based on the information obtained in the job advertisements and in the theoretical apparatus. As a conclusion, we point out that: (i) the Pedagogy course has a great potential for employability, within the degrees it is the course that most employs; (ii) that in non-formal spaces of education the pedagogue exercises a multiplicity of practices and that some are far from their educational axis (III) that corporate pedagogy is a prosperous and rising field with the prospect of projecting the graduate in Pedagogy in contexts of very diverse practices, however, we call attention to the process of precariousness of the profession that is installed in this displacement. This displacement of the pedagogue to other spaces is also the focus of discussion among specialists in the field of Education.
\end{abstract}

Keywords: Business Education; Education; Formal and non-formal spaces; Contexts.

\title{
INTRODUÇÃO
}

O século XXI protagoniza um dos mais emblemáticos contextos da história da humanidade, marcada pela primeira grande onda do Covid-19. Olharemos para os processos educacionais utilizando como marcadores históricos o antes e o depois da pandemia. Os ideais neoliberais implementados mundo afora no final do século XX e início do século XXI têm alargado as discussões no âmbito da educação em várias vertentes, entre elas podemos citar: o currículo dos cursos de licenciatura - diante das Resoluções 02/2015 e 02/2019, os perfis de licenciados que estamos a formar ou que queremos formar, a Base Nacional Comum Curricular (BNCC) e seus polêmicos termos - habilidades, competências e itinerários - e a forma como isso vem reverberando na educação e, consequentemente, na formação de professores. Tudo isso, somado com o saldo que deixará a pandemia do Covid-19, nos coloca num universo educacional e profissional marcado por incertezas. As mudanças que possivelmente virão no pós-pandemia poderão acelerar o processo de educacionalização da educação, um exemplo disso é a discussão que se organiza em torno do hibridismo nos mais 
variados níveis da educação. Esse assunto tem causado dilemas e tensões para formação docente, que precisa se estabelecer e se (re) configurar nesse novo cenário.

No contexto atual, um foco muito grande tem sido dado à formação de professores para além dos espaços educacionais. Percebe-se que a intencionalidade dessa busca constante pela qualificação do/a pedagogo/a está na necessidade de atender um mercado que exige cada vez mais dessa categoria desenvolvimento profissional e qualificação para atuar em contextos diversos e competitivos. O currículo multidisciplinar do curso de Pedagogia, perpassado por vários conteúdos e áreas, possibilita isso. Nessa perspectiva, colabora Libâneo (1999) ao afirmar que: "É quase unânime entre os estudiosos, hoje, o entendimento de que as práticas educativas estendem-se às mais variadas instâncias da vida social, não se restringindo, portanto, à escola e muito menos à docência embora estas devam ser a referência da formação do pedagogo escolar." (p. 116).

Nesses espaços não formais de educação, o/a pedagogo/a tem a "função de melhorar a qualidade das relações sociais e humanas dentro das empresas" (PIUNA, PURIFICAÇÃO, SANTANA, 2016, p. 2), podendo, assim, promover "mudanças e melhorias no ambiente de trabalho e na prestação de serviços, garantindo uma atuação mais eficiente no mercado competitivo" (p.2). Por isso, Libâneo afirma que "o campo de atuação do profissional formado em pedagogia é tão vasto quanto são as práticas educativas na sociedade. Em todo lugar onde houver uma prática educativa com caráter de intencionalidade, há aí uma Pedagogia" (LIBÂNEO, 2016, p. 116).

No entanto, chamamos a atenção para o cuidado com a precarização da profissão do pedagogo. A reestruturação produtiva do capital, cravado no discurso neoliberal, tem apresentado cenários utópicos, transvestidos de oportunidades de trabalho. Essa especializada flexivel que é dada ao pedagogo, chamando-o de pedagogo empresarial, se não estruturada nas Diretrizes Nacionais para Curso de Pedagogia (DNCP) e nas competências e habilidades do pedagogo previstas nesse aparato, pode colaborar para desqualificar, desorganizar e precarizar o trabalho do pedagogo. (CLARKE, 1991).

Para fundamentar o referencial metodológico do trabalho, buscamos em Köche (1997) respoaldo que justificasse a utilização do estudo qualitativo/ exploratório, em que analisamos 40 anúncios des vagas para pedagogo empresarial, junto ao $\mathrm{CATHO}^{1}$, no período de março a novembro de 2020. O foco do estudo era extrair alguns marcadores julgados como importantes na constituição da identidade profissional do/a pedagogo/a nos espaços não formais de educação, buscando responder a seguinte indagação: 'Quais competências e

\footnotetext{
${ }^{1}$ Catho é um site brasileiro de classificados de empregos. Sua sede fica localizada em Barueri, no estado de São Paulo.Disponível em: https://www.catho.com.br/vagas/pedagogo-

empresarial/?q=Pedagogo\%20Empresarial\&page=2. Acessado em 21/11/2020.
} 
habilidades intercruzam a identidade profissional do/a pedagogo/a nos espaços não formais de educação?'.

\section{DIÁLOGOS TEÓRICOS}

Esta sessão encontra-se dividida em dois tópicos, que nós ousamos chamar de o côncavo e convexo da formação de professores. Trazemos, na primeira parte, a educação, os cursos e as instituições de ensino pensados a partir da ótica do processo de educacionalização - nesse processo, percebe-se a constante necessidade de mudanças no currículo, na função principal das instituições e a centralização do professor no ensino. Tudo isso, de certa forma, vem colaborando para as instituições de ensino (do nível básico ao superior) passem por um processo de (re) configurações. Entender esse processo é crucial para compreendermos o perfil de pedagogo que estamos a formar e quais os interesses sociais que gravitam sobre essa formação.

No segundo tópico dessa sessão, trazemos o pedagogo se deslocando para além das atividades de docência, indo desenvolver funções no âmbito empresarial. O desejo empresarial no pedagogo está no fato de esse receber uma formação multidisciplinar que agrega conhecimentos e práticas os quais perpassam a educação e outras áreas. Mesmo sendo as licenciaturas e, de forma especial a pedagogia, alvo de críticas e exclusão social por parte de alguns indivíduos, que as veem como cursos inferiores, devido à falta de políticas públicas e de valorização profissional, a busca por pedagogos para atuarem nos espaços não formais de educação ainda é uma crescente. Nesses espaços, o pedagogo empresarial pode se especializar na execução de duas grandes demandas empresariais - funcionalismo ou no produto da empresa. Para melhor esclarecimento sobre essa funcionalidade do pedagogo empresarial, organizamos um ciclo de diálogos entre teóricos dessa temática, para que pudessem nos apresentar as especificidades dessa função.

\section{EDUCACIONALIZAÇÃO COMO PROCESSO DE MODERNIZAÇÃO}

Nos últimos anos, o contexto educacional brasileiro vem sendo atravessado pelos ideais neoliberais, que trazem em seu bojo a propagação de políticas de assistência social e pari passu, vem o fenômeno da educacionalização do social. Segundo Lockamann (2016), “educacionalização do social é o fenômeno/obsessão contemporânea pela educação, onde essa assume um papel salvífico, sendo apontada como instância de solução para uma variedade de problemas sociais, que se vinculam a áreas bastante distantes” (p. 59). Nas concepções de Smeyers e Depaepe (2008), a educacionalização do social é um "conceito central para 
identificar a orientação global ou a tendência de pensar a educação como o ponto central para abordar ou resolver maiores problemas humanos" (p.379)

Com isso, temos aí um processo de alargamento das funções da universidade, que aos poucos vai se afastando de sua função precípua e assumindo o papel de condução de condutas. Com isso, fenômeno da educacionalização "incide consideravelmente sobre as instituição de ensino, produzindo o que chamamos de (re) configurações institucional. Entre os modelos de (re) configurações, citamos:o papel expansionista da universidade contemporânea e a redefinição daquilo que até então era entendido como conhecimento" (p.59). As implicações advindas desse fenômeno reverberam nos currículos - trazendo mudanças bruscas na rota dos processos de ensino e aprendizagem, impactando, ainda, o processo de construção de identidades dos sujeitos que estamos aa formar.

Na linha dessas ideias, vários são os autores brasileiros que vêm dialogando sobre a função social das instituições de ensino, entre os quais citamos: Julio Groppa Aquino (2012), Silvio Gadelha Costa (2009), Elí Fabris e Clarice Traversini (2011), Alfredo Veiga-Neto (2008), assim como Antônio Flávio Moreira e Vera Candau (2007). Segundo Gadelha (2009), as instituições de ensino têm sido frequentemente acionadas como elemento complementar e até mesmo essencial para a viabilização de iniciativas, programas e/ou campanhas que envolvam as mais diversas dimensões da vida humana.

No momento atual, essa discussão é crucial, pois temos aí uma Base Nacional Curricular recém aprovada, que vem sendo alvo de fortes críticas de pesquisadores e associações vinculadas à educação devido ao seu caráter de educacionalização social, em que as palavras de ordem são: competências, habilidades e itinerários.

Todas essas mudanças no currículo advindas da BNCC reverberam também no perfil de pedagogos e licenciados de áreas específicas que estamos a formar nos cursos e programas de formação de professores no Brasil. Para além disso, os cursos de Pedagogia e as demais licenciaturas ainda estão sobre os impactos das resoluções 02/2015 e 02/2019 que determinam as diretrizes para a formação de professores no Brasil. Essa última foi aprovada em dezembro de 2019, sobre fortes críticas de instituições e organizações educacionais, haja vista o distanciamento dos projetos focados na teoria e nas discussões dos fenômenos educacionais, para um alargamento de práticas, que aos olhos de especialístas enfraquece a formação do licenciado. Isso reforça a dualidade existente entre os bacharelados e as licenciaturas, em que essa segunda modalidade, muitas das vezes é vista com o perfil de inferioridade. A partir dessa percepção, a Pedagogia e as outras licenciaturas encontram-se no circuito do ensino superior, sob o julgo da exclusão. 
Para Lockmann (2016, p. 60-61), “o fenômeno da educacionalização do social pode ser visualizado por meio do movimento operado pelas estatísticas, o qual vincula, numérica e discursivamente, uma variedade de problemas sociais ao campo da Educação", entre eles, a exclusão. "Torna-se urgente, questionar os usos alargados da palavra exclusão, quando ela é entendida como "o outro da inclusão". Nesse caso, excluídos referem-se àqueles que, de alguma maneira, são discriminados pelo Estado e/ou pela sociedade”. (VEIGA-NETO e LOPES, 2011, p.122). Os autores ainda falam sobre "o caráter natural que é atribuído à inclusão, entendendo que as políticas que a promovem, bem como os usos da palavra inclusão em circulação, afinam-se tanto com a lógica do binário moderno inclusão x exclusão quanto com a lógica contemporânea em que a inclusão funde-se com a exclusão. É em decorrência de tal fusão que, de uns anos para cá, temos grafado in/exclusão” (p.125)

\section{A PEDAGOGIA EMPRESARIAL}

Não é de agora a integração entre educação e trabalho. Essa junção já vem de longas datas direcionando o processo histórico da evolução empresarial. No entanto, data-se da Revolução Industrial (século XVIII), para expressar um paradigma de mudanças, em que a educação passa a ser vista a partir de uma perspectiva única, tornando-se elemento central do processo de desenvolvimento humano. (SAVIANI, 2008). Para o autor, o novo contexto demanda ir além dos tradicionais aspectos do "ler e do contar". Pecerbe-se a necessidade da qualificação educacional e profissional, avançar para além desses dois aspectos, na perspectiva de colaborar com o desenvolvimento do setor ecnômico e do setor industrial.

Olhando esse deslocamento da educação para o centro dos processos, que implicará no desenvolvimento social/ econômico, compreendemos o que Maron (2007) chama de necessidade de novos perfis de trabalhador, com múltiplas competências e habilidades, entendo, que esse processo caminha, pari passu com a necessidade do mercado. Nessa linha de pensamento, há quem defenda a urgente necessidade de uma educação que perpasse pelo empresarial, vindo colaborar com a construção de um perfil de trabalhador que atenda cada vez mais as complexidades do setor. Mas há também quem defenda uma educação focada no individuo e no seu desenvolvimento humano. Por isso, temos hoje instituições formativas e cursos com perfis diferenciados. Neste trabalho não objetiva-se falar sobre educação com foco no mercado ou no indivíduo, mas focar nas discussões que giram em torno da atuação do pedagogo em espaços não formais de educação.

Pensar um/a pedagogo/a para além da sala de aula e do exercício da docência nos remete a refletir sobre vários aspectos, entre eles, podemos citar: a insatisfação com a docência e às atuais condições de trabalho e valorização profissional. Para esses aspectos, 
pontuamos que, enquanto não houver políticas públicas, com foco na valorização e no respeito aos profissionais da educação, haverá sempre o deslocamento desses profissionais para outros setores. Para além desses, temos outros fatores que vinculam-se às múltiplas identidades, que se afloram durante o processo de formação inicial do/a pedagogo/a, dando ao/a mesmo/a a pção de escolha de atuação profissional.

Lorenzo (2003) apresenta a Pedagogia como campo vasto de atuação, mostrando, inclusive, que esse campo educativo em que o pedagago se insere vai além dos espaços formais, abrindo fortes perspectivas de atuação em empresas, consultorias e outros setores. Segundo autor, as instituições/ organizações primam por novos perfis na gestão do conhecimento e, nesse contexto, o pedagogo muito poderá contribuir, trazendo novas ideias, conceitos e soluções, principalmente no que tange às dinâmicas de grupos e relações intrepessoais.

Para Ribeiro (2010) e Trevisan e Lameira (2003),“A pedagogia empresarial se ocupa basicamente com os conhecimentos, as competências, as habilidades e as atitudes diagnosticados como indispensáveis/ necessários à melhoria da produtividade" (RIBEIRO, 2010, p. 13), sendo assim, consisderada uma atividade potencializadora do campo da organizacional, afirmam (TREVISAN e LAMEIRA, 2003). Nas concepções de Cadinha (2007), a Pedagogia empresarial pode ser vista como uma ponte que integra a ampliação do conhecimento do indivíduo com as táticas organizacionais. Algumas dessas táticas perpassaam pelas relações interpessoais e pela busca de resoluções dos conflitos oriundos dessas relações, por isso, Ribeiro (2005), justificando a presença do pedagogo nas empresas, salienta que esse/a profissional possui em sua trajetória formacional um aparato de conhecimentos que, colocados em prática, podem vir a colaborar na melhoria das relações entre os pares, colaborar no trabalho de valorização dessas e no desenvolvimento de sua autoestima.

Pontuamos ainda as concepções de autores como Laudares e Quirino (2006), Ribeiro (2010), Holtz (1999), Lopes (2006) e Frison (2001), no que tange à pedagogia empresarial. Nessa perspectiva profissional, na qual inserimos a Pedagogia empresarial, acontecem atos de direcionamentos, deslocamento e operacionalização da educação do operário nas empresas (LAUDARES e QUIRINO, 2006). O pedagogo empresarial aparece como líder, que desenvolve novos líderes e promove uma interação entre esses e o corpo institucional. Ao assumir e compreender a dimensão de seu papel dentro da instituição, o pedagogo empresarial demonstra seu grau de desenvolvimento, possibilitando aos demais membros da equipe que também se desenvolvam (RIBEIRO, 2010, grifa-se). Olhando todo esse processo marcado pelo desenvolvimento pessoal e do pessoal, Holtz (1999) salienta que "esse processo de 
mudança provocada no comportamento das pessoas em direção a um objetivo chamamos de aprendizagem e aprendizagem e é a especialidade da Pedagogia” (p. 6). A partir dessa concepção teórica, compreende-se que, seja na escola ou na empresa, o pedagogo tem a missão de ensinar. Nessa linha de pensamento, Lopes (2006) esclarece que a pedagogia empresarial "promove a reconstrução de conceitos básicos, como criatividade, espírito de equipe e autonomia emocional e cognitiva" (p.74). E, nesse contexto, "viver é aprender continuamente, é aprender a trabalhar em equipe propiciando a integração e fortalecendo laços" (FRISON, 2001, p. 101).

\section{METODOLOGIA}

O objetivo do presente estudo é analisar, a partir de anúncios de trabalhos, a inserção de pedagogos no mercado, em espaços não formais de educação, no contexto temporal de março a novembro de 2020. Para dar conta desse objetivo, optamos pela abordagem qualitativa uma vez que seu foco está no caráter subjetivo do objeto analisado, buscando assim compreender suas particularidades e experiências individuais. Diante o exposto, parece ser mais adequada a estudos dessa natureza, os quais apoiaremos no plano de investigação exploratória e no estudo de caso (BOGDAN; BIKLEN, 1994).

A abordagem qualitativa admite expor um fenômeno em profundidade através da apreensão de significados e dos estados subjetivos dos informantes chave, prevalecendo a tentativa de capturar e compreender, o melhor possível, as perspectivas e os pontos de vista dos sujeitos sob determinado problema (BOGDAN; BIKLEN, 1994). Na linha dessas ideias, Merriam (1998, p. 6) salienta que na investigação qualitativa "a realidade é construída pelos indivíduos que interagem nos seus ambientes sociais". E Minayo (2001) salienta que a abordagem qualitativa "trabalha com o universo de significados, motivos, aspirações, crenças, valores e atitudes, o que corresponde a um espaço mais profundo das relações, dos processos e dos fenômenos que não podem ser reduzidos à operacionalização de variáveis" (2001, p. 14). Para isso, foi utilizada a revisão de literatura, a qual nos possibilita buscar, analisar, descrever, tendo como parãmetros estudos já realizados sobre o tema, assim pode abarcar livros, artigos de periódicos, teses e dissertações e outros tipos de publicações.

"Pesquisa Interpretativa (Descritiva, Fenomenológica): orienta a descrever e interpretar os fenômenos sociais ou educativos e se interessa pelo estudo dos significados e intenções das ações humanas desde a perspectiva dos próprios agentes sociais". Nesse contexto, a utilização de um método que visa discorrer sobre os diversos conhecimentos que um professor deve ter para desenvolver aprendizagens em seus alunos é muito bem-vindo. $\mathrm{O}$ caminho percorrido pela estudante concluinte adota a revisão sistemática em seu estudo, 
sendo demarcado pela indispensabilidade de critérios objetivos e consistentes para selecionar os dados que irá guiar a solução da pergunta norteadora. E para isso, adotam-se os seguintes passos:

i) Formulação da pergunta - Ação: Definiu a pergunta científica especificando população e intervenção de interesse.

ii) Localização e seleção dos anúncios de vagas para pedagogia empresarial - $\underline{\text { Ação: }}$ Estabeleceu como critérios para a seleção dos anúncio no site do CATHO, o marco temporal de março a novembro de 2020 e a espeficidade do cargo -Pedagogia Empresarial.

iii) Coleta e análise de dados - Ação: Aplicou os critérios na seleção - Conduziu a busca na base de dados Portal de Teses e Dissertações da CAPES e com base na(s) estratégia(s) definida(s ) e justificou as exclusões do trabalho, que foram: não ter como tema de pesquisa a Pedagogia Empresarial e no caso de os anúncios estarem fora do marco temporal.

\section{RESULTADOS E DISCUSSÕES}

Para construção dessa sessão, acompanhamos, no período de março a novembro de 2020, os anúncios para vaga de Pedagogo Empresarial no site do CATHO - que é um site de abrangência nacional sendo utilizado por empresas para anunciar suas vagas e por pessoas que estão à procura de uma colocação no mercado de trabalho - Devido a esse perfil de classificados de empregos e amplitude do site, que atende todo o território nacional, foi que o escolhemos como lócus de nossa observação. Para organização do trabalho, fixamos alguns marcadores, como elementos essenciais para pesquisa: (i) Pedagogia Empresarial; (ii) atribuições; (III) salário valorização profissional e (IV) cidade da vaga. Apresentamos abaixo

\section{o quadro I - Modelos de anúncios e vagas para Pedagogo Empresarial.}

\begin{tabular}{|c|c|}
\hline Vaga & Atribuições \\
\hline $\begin{array}{l}\text { Analista Gente e Gestão } \\
(01 / 10 / 2020) \text {-Pernambuco }\end{array}$ & $\begin{array}{l}\text { Acompanhamento da rotina das áreas avaliando a efetividade dos processos e } \\
\text { alinhamento com a metodologia e cultura ágeis; Revisão das reuniões, gestão } \\
\text { dos indicadores e implementação de novos processos; Consolidação dos } \\
\text { aprendizados dos testes realizados para servir de benchmarking Brasil. }\end{array}$ \\
\hline $\begin{array}{l}\text { Assistente de Treinamento e } \\
\text { Desenvolvimento } \\
(11 / 11 / 2020)-\text { Rio de } \\
\text { Janeiros }\end{array}$ & $\begin{array}{l}\text { Ministrar as ações de treinamento, elaborar e executar programas de } \\
\text { treinamentos, desenvolver conteúdos para treinamentos e avaliar resultados } \\
\text { alcançados em cada ação. Elaborar e ministrar os treinamentos da área, } \\
\text { reportando os resultados. Auxiliar e apoiar a área na condução de pesquisa de } \\
\text { clima e comunicados. Preparar relatórios com o planejamento e resultados dos } \\
\text { treinamentos. Criar e acompanhar indicadores de treinamento, sinalizando } \\
\text { desvios e apontando soluções. Monitorar os resultados da área, contribuindo } \\
\text { com melhoria de processos. Contribuir para melhorar o desempenho da equipe } \\
\text { de atendimento ao cliente, por meio de atuação com a área de qualidade } \\
\text { interna. Acompanhar presença dos colaboradores em treinamentos presenciais } \\
\text { e online. Elaborar treinamentos com foco em desenvolvimento pessoal. } \\
\text { Efetuar lançamentos de avaliação de reação dos treinamentos no sistema, a fim } \\
\text { de atender as demandas da área. Elaborar e acompanhar o cronograma de } \\
\text { treinamento. }\end{array}$ \\
\hline
\end{tabular}


Fonte: CATHO/2020 - Acesso 20/11/2020

Os anúncios acima apresentam algumas das atribuições destinadas ao pedagogo empresarial em exercício de suas funções. Percebe-se uma estreita aproximação com a formação do pedagogo. Essa baixa aproximação com os elementos da formação inicial vai requerer do pedagogo que, ao assumir a vaga, busque por novos conhecimentos, principalmente do campo da administração e gestão. Tomando por base o Parecer $\mathrm{CNE} / \mathrm{CP} \mathrm{n}^{\circ}$ 05/2005, amplia-se a área de atuação do pedagogo para além das atividades educacionais escolares. Percebe-se que a atuação do pedagogo empresarial como dinamizador de projetos e experiências educacionais em espaços formais e não formais é concebida. No entanto, é importante frisar que outros aparatos legais posteriores vêm praticizando essa atuação do pedagogo e delimitidando sua identidade profissional e perfil de atuação.

Também encontramos como resultados dos marcadores outras referências, conforme mensionadas abaixo:

Atuar como Bussiness Partner. Gerenciar mudança de cultura. Reestruturar setor de RH. Desenvolvimento liderança e Atendimento. Fazer seleção baseada em valores. • Conhecer tudo em gestão de pessoas. Ter experiência com mudanças culturais.(CATHO, 2020 - Fortaleza - CE).

Responde pelas atividades de consultoria, em assuntos referentes à área de Recursos Humanos, compreendendo: diagnósticos, planejamento estratégico de atuação, desenvolvimento dos trabalhos, propondo alternativas e soluções à Direção da empresa. - Ensino superior completo em Psicologia. Possuir experiência anterior. Disponibilidade para viagens. Conhecimentos em Pacote Office, Recursos humanos e teste psicológico (CATHO, 2020 - Fortaleza - CE).

Responsável pelo desenvolvimento e implantação de estratégias de Recursos Humanos e iniciativa alinhadas com a estratégia do negócio em geral; conciliar as relações da gestão e funcionários, resolvendo demandas adversas; gerenciar todos os subsistemas de Recursos Humanos, como Recrutamento e Seleção, Treinamento e Desenvolvimento, Estratégia Organizacional; dentre outras atividades pertinentes a função (CATHO, 2020 - Goiânia - GO)

As atribuições acima, nos referidos anúncios, não vêm direcionadas ao público específico da Pedagogia. Em alguns desses anúncios, a exigência para vaga é ensino superior em cursos como: Pedagogia, Psicologia, Direito, Administração, Ciências Contábeis, Gestão e Informática. Olhando todas essas áreas, entendemos o porquê do alargamento das atribuições. Muitas empresas querem um profissional que traga em seu bojo de formação e atuação os perfis (conhecimentos) de várias outras áreas. A falta de uma maior aproximação dessas atribuições com as prescrições curriculares do curso de Pedagogia pode ser um indicador de precarização do trabalho do pedagogo.

Cabe salientar que também nos deparamos com vagas anunciadas para pedagogo empresarial, mas que a atuação estava diretamente focada no campo da educação (formal/

\footnotetext{
${ }^{2}$ Disponível em: https://www.catho.com.br/vagas/pedagogia-empresarial/?q=Pedagogia\%20empresarial.
} Acessado em 20/11/2020. 
não-formal). Nesse tipo de vaga, as atribuições dialogam com o perfil de formação do pedagogo:

Contribuir na elaboração das políticas e metodologias educacionais segundo os princípios Institucionais, as orientações da Diretoria, o Regimento da Unidade e a legislação vigente; Realizar acompanhamento de educadores/ docentes (no que se refere a seus planejamentos, projetos, sistematização); Participar dos projetos e ações desenvolvidas pelas demais áreas da Unidade; Contribuir com o acompanhamento e avaliação do desempenho dos profissionais do núcleo pedagógico, pautado nas políticas institucionais; Participar das reuniões da Equipe Interdisciplinar a respeito dos processos pedagógicos; Participar da organização e desenvolvimento de atividades coletivas (eventos pedagógicos); Realizar acompanhamento da aprendizagem dos educandos; Participar dos Conselhos de Classe municiando com informações e estratégias; Realizar atendimento com as famílias visando o desenvolvimento pedagógico do estudante; Fazer cumprir as questões disciplinas da escola REQUISITOS: Superior completo em Pedagogia; Pós-Graduação em Orientação Escolar; (CATHO, 2020, Brasília-DF).

Isso implica dizer que temos, sim, empresas que buscam implementar seu desenvolvimento, trazendo para as suas equipes pedagogos dinâmicos e proativos. Mas também temos empresas cujo foco está no lucro e no faturamento e, para alcance dessas metas, contratam pedagogos, na faixada pedagogo empresarial, para se uberizarem em funções diversas. Cabe ainda salientar que faixa salarial para o pedagogo empresarial varia de $\mathrm{R} \$ 1001,00$ a $\mathrm{R} \$ 5.0000,00$.

\section{CONSIDERAÇÕES FINAIS}

As análises desenvolvidas neste trabalho de conclusão de curso que teve como objetivo analisar, a partir de anúncios de trabalhos, a inserção de pedagogos no mercado em espaços não formais de educação, no contexto temporal de março a novembro de 2020, sinalizam para duas perspectivas importantes. A primeira, que as vagas ofertadas para pedagogo empresarial nem sempre são pensadas a partir do perfil desse profissional. Percebese uma necessidade de agregar perfis diversos em um único profissional, mudando bruscamente sua identidade profissional. O segundo é, como disse o nosso corpo teórico no que tange à Pedagogia empresarial, ela é uma perspectiva de campo de atuação do pedagogo, o problema é que se tornou uma área muito aberta e sem uma delimitação de função específica.

Para evitar o processo de precarização e flexibilização do trabalho do pedagogo, sugere-se uma aproximação maior das funções propostas pelas empresas às especificadas nas Diretrizes Curriculares Nacionais do Curso de Pedagogia (DCNP), que, aliás, já deveriam ter sido ajustadas para atender a outros aparatos legais que incidem na identidade do pedagogo, tais como: BNCC, Resolução nº 02/2015 e Resolução nº 02/2019. E assim alinhar o discurso. Entende-se que o papel do pedagogo está alinhado à mediação dos processos educativos na sociedade, seja ele dentro ou fora das escolas. E, com isso, apresentamos os três últimos 
pontos de nossas observações: (i) o curso de Pedagogia tem um grande potencial de empregabilidade, dentro das licenciaturas é o curso que mais emprega; (ii) que em espaços não formais de educação o/a pedagogo/a exerce uma multiplicidade de práticas e que algumas estão bem distantes do seu eixo de formação (III) que a Pedagogia empresarial é um campo próspero e em ascensão com perspectiva de projetar o/a licenciado/a em Pedagogia em contextos de práticas bem diversificados, no entanto, chamamos a atenção para processo de precarização da profissão que se instala nesse deslocamento. Esse deslocamento do pedagogo para outros espaços também é foco de discussão entre especialistas da área da Educação.

\section{REFERÊNCIAS}

BOGDAN, R.; BIKLEN, S. Investigação Qualitativa em Educação - uma introdução à teoria e aos métodos. Porto: Porto Editora, 1994.

CADINHA, M. Conceituando pedagogia e contextualizando pedagogia empresarial.Pedagogia Empresarial: forma e contextos de atuação. Rio de Janeiro: Wak, 2007.

CATHO. Site brasileiro de classificados e empregos. 2020. Disponível em: https://www.catho.com.br/. Acessado em: 21/11/2020.

CLARKE, Simon. Crise do Fordismo ou Crise da Social-Democracia? São Paulo: Lua Nova, 1991.

DEPAEPE, Marc e SMEYERS, Paul. Educacionalização como um processo de modernização em curso. In. Perspectiva, Florianópolis, v. 34, n. 3, 753-768, set./dez. 2016

FRISON, Lourdes Maria Bragagnolo. O pedagogo nos espaços não escolares: novos desafios. In: ANAIS do Seminário Interdisciplinar em Supervisão escolar: a gestão dos processos educativos. Organização: Carla Lavínia Pacheco da Rosa e Rudimar Serpa de Abreu. Santa Cruz do Sul: UNISC, 2001.

HOLTZ, Maria Luiza Martins. Lições de Pedagogia Empresarial. Sorocaba-SP: MH Assessoria Empresarial S/C Ltda, 1999.

KÖCHE, José Carlos. Fundamentos de Metodologia Científica: teoria da ciência e prática da pesquisa. Petrópolis, RJ: Vozes, 1997.

LAUDARES, J; QUIRINO, R. O Pedagogo do Trabalho: Perfil Profissional e Saberes Necessários para a Atuação. In.: Educação \& Tecnologia, v. 15, p. 73-94. 2006.

LIBÂNEO, José Carlos. Pedagogia e pedagogos: inquietações e buscas. In: Anais do $2^{\circ}$ Encontro Cearense de Educadores, promovido pelo OfinArtes - Centro de Acessória Pedagógica, Fortaleza, 1999.

LOPES, Izolda. TRINDADE, A B. CARVALHO, Cláudia e CADINHA, Márcia Alvim. Pedagogia Empresarial uma nova visão de aprendizagem nas organizações. Rio de Janeiro: Wak Editora, 2006. 
LORENZO, Francine De. Aprendendo a aprender: empresas descobrem a importância da educação no trabalho e abrem as portas para o pedagogo. In.: Revista Vencer, março de 2003.

LOCKMANN, Kamila. A educacionalização do social e as implicações na escola contemporânea. In.: Educação Unisinos, 20(1): 58-67, janeiro/abril 2016.

MARON, N. Reestruturação Produtiva, Escolarização Fabril e o Processo Histórico de Inserção do Pedagogo na Fábrica: Estudos de Caso na Região de Curitiba. In.: Revista Eletrônica de Ciências da Educação, v.6, n.2, novembro. 2007.

MERRIAM, S. B. Qualitative Research and Case Study Applications in Education. SanFrancisco: Allyn and Bacon, 1998.

MINAYO, M. C. S. Ciência, técnica e arte: o desafio da pesquisa social. In: MINAYO, M. C. S (Org.). Pesquisa social: teoria, método e criatividade. Petrópolis, RJ: Vozes, 2001. p. 0929.

PIUNA, Geisa Morais, PURIFICAÇÃO, Marcelo Màximo. SANTANA, Maria Luzia da Silva. Pedagogia empresarial: o desenvolvimento eficiente de atividades pedagógicas no mercado de trabalho - a abertura para novas atividades. In.: Anais do I Colóquio de Pesquisa Multidisciplinar, - 06, 07 e 08 de junho - Mineiros-GO, 2016.

RIBEIRO, A. E. A. Pedagogia Empresarial: atuação do pedagogo na empresa. $2^{a}$ edição, Rio de Janeiro: WAK, 2004.

Wak Editora, 2003.

Pedagogia Empresarial: atuação do pedagogo na empresa. Rio de janeiro:

. Pedagogia Empresarial: atuação do pedagogo na empresa. $6^{\circ}$ Edição. Rio de Janeiro: Wak Editora, 2010.

- Temas atuais em pedagogia empresarial: aprender para ser competitivo. $3^{\text {o }}$ edição - Rio de Janeiro: Wak Editora, 2010.

SAVIANI, D. A Pedagogia no Brasil: História e Teoria. Campinas, São Paulo. 2008.

TREVISAN, N. V. LAMEIRA, L. J. C. R. Formação do educador para pedagogia nas empresas.

Disponível

em:

https://periodicos.ufsm.br/educacaoespecial/article/view/5033\#: :text=Em\%20vez\%20de\%20 lutar\%20contra,num\%20ambiente\%20oscilante\%20e\%20ins. Acesso em Março de 2016.

VEIGA-NETO, A.; LOPES, M. C.. Inclusão, exclusão, in/exclusão. 2011. Disponível em: https://revistas.pucsp.br/index.php/verve/article/view/14886. Acesso em Março de 2016.

Artigo Recebido: 03 de abril de 2021 .

Artigo Aceito: 17 de maio de 2021. 